\title{
Influence of Annealing on the Photoconversion Efficiency of Titania Nanotube Arrays
}

\author{
D. Pathinettam Padiyan ${ }^{\mathrm{a} *}$ and S. T. Nishanthi ${ }^{\mathrm{a}}$ \\ ${ }^{a^{*}}$ Department of Physics, Manonmaniam Sundaranar University, Tirunelveli - 627 012, Tamil Nadu, India \\ Fax : +91- 4622334363, e-mail : dppadiyan@msuniv.ac.in
}

Titania nanotubes are prepared by two-step electrochemical anodization of titanium foil and the influence of annealing $(1,2,3,4 \& 5 \mathrm{~h})$ is reported. Increase in crystalline nature with increase in annealing time is observed in X-ray diffraction (XRD) studies. The effect of annealing on morphology of the nanotubes is clearly seen in High Resolution Scanning Electron Microscope (HR-SEM) analysis. The diffuse reflectance spectra (DRS) studies reveal that the increase of annealing time brings the titania nanotubes optical absorption from UV to visible region. The $4 \mathrm{~h}$ annealed sample shows the higher photoconversion efficiency of $18.93 \%$. This enhancement is attributed to the improved crystallinity, anatase phase with lesser band gap.

Key words: titania, anatase, annealing time, photoconversion efficiency

\section{INTRODUCTION}

$\mathrm{TiO}_{2}$ is a n-type semiconductor having a wide band gap of $3.2 \mathrm{eV}$ and it can decompose large number of organic and inorganic pollutants. ${ }^{1-3}$ One dimensional $\mathrm{TiO}_{2}$ nanostructure has been of great interest in photoelectrochemical (PEC) water splitting, ${ }^{4,5}$ solar cells, ${ }^{6}$ gas sensors ${ }^{7}$, photocatalytic degradation ${ }^{8}$ and bio-medical fields ${ }^{9}$. Among the three polymorphs of $\mathrm{TiO}_{2}$, anatase and rutile are tetragonal in structure, whereas brookite possess orthorhombic. Anatase phase is the most photoactive phase compared to rutile and brookite. ${ }^{10}$ Titania $\left(\mathrm{TiO}_{2}\right)$ nanotubes have been prepared by various methods such as sol-gel, hydrothermal, electrochemical anodization etc. ${ }^{11-13}$ Among these, the two-step electrochemical anodization is the most convenient and simple method for the preparation of highly ordered titania nanotubes. ${ }^{14}$ However, mostly titania nanotubes fabricated by anodization is amorphous in nature and thus they limit the photoelectrochemical applications. Annealing is one of the common methods to reduce the defects, improve the crystalline nature and morphology of the titania nanotubes. Allam et al. ${ }^{15}$ reported the variation of photoconversion efficiency with different annealing conditions and the efficiency of $13.13 \%$ \& $10 \%$ for IR annealed and thermally annealed titania nanotubes respectively. In this work, a two-step electrochemical anodization is involved to fabricate highly ordered titania nanotubes and their photoelectrochemical properties were discussed. To the best of our knowledge there is no report on increase in photoconversion efficiency with respect to annealing time.

\section{EXPERIMENTAL DETAILS}

Before anodization, titanium (Ti) foil with a thickness of $1 \mathrm{~mm}$ was degreased using acetone and double distilled (DD) water followed by chemically polished in $(1: 4: 5) \mathrm{wt} \%$ of $\mathrm{HF}: \mathrm{HNO}_{3}$ :DD water for few seconds. Then the foils were ultrasonically cleaned in DD water for $5 \mathrm{~min}$ and finally dried in air. An aqueous electrolyte including a 0.3 wt $\%$ ammonium fluoride $\left(\mathrm{NH}_{4} \mathrm{~F}\right), 1$ vol $\% \mathrm{H}_{2} \mathrm{O}$ in ethylene glycol (EG) was prepared. The anodization was performed in a two-electrode electrochemical cell with a Ti foil as working electrode and a flag shaped platinum $(\mathrm{Pt})$ foil as the counter electrode. In the first step, Ti foil has been anodized at $30 \mathrm{~V}$ for $1 \mathrm{~h}$ and the layer was removed by sonicating in DD water for $30 \mathrm{~min}$. Then this pretreated Ti substrate was used as anode again for the second step anodization at $30 \mathrm{~V}$ for $15 \mathrm{~min}$ and the nanotube arrays were grown. All the above experiments were carried out at room temperature under constant stirring. The as-anodized titania nanotubes were found to be amorphous in nature, and therefore annealed to convert it into crystalline. The asanodized nanotubes were annealed at optimized temperature of $580{ }^{\circ} \mathrm{C}$ for five different times such as $1,2,3,4$ and $5 \mathrm{~h}$ in air atmosphere with a heating and cooling rate of 8 ${ }^{\circ} \mathrm{C} / \mathrm{min}$.

The crystalline nature and the phase of the titania nanotube was confirmed from X-ray diffraction pattern obtained using PANalytical XPERT PRO X-ray diffractometer with $\mathrm{Cu} \mathrm{K \alpha}$ radiation source $(\lambda=1.54 \AA)$. The surface morphology of the titania nanotube was characterized using FEI Quanta High Resolution Scanning Electron Microscope (HR-SEM) and their elemental composition was analyzed by Energy Dispersive X-ray Spectroscopy (EDS, fitted with the HR-SEM instrument). The optical studies were done by Diffuse Reflectance Spectroscopy (DRS, Varian Cary 5E UV-VIS-NIR instrument) in the wavelength region of $200-800 \mathrm{~nm}$.

Photoelectrochemical properties of all the titania nanotubes were characterized using a home-made glass setup of two-electrode PEC cell with titania nanotube as the photoanode and a Pt coil as the cathode. The anode and cathode compartment were provided with a pipette made of 
glass with graduation for quantitative measurements. Hydrogen gas evolved at the photoanode was collected and the volume of hydrogen gas was measured by directly reading the variation in electrolyte level. Water splitting experiment was carried out in $1 \mathrm{M}$ aqueous $\mathrm{KOH}$ electrolyte without and with ethylene glycol (EG). A xenon lamp (Wacom model XDS-501S) was used as the light source to irradiate the photoanode through a quartz window. The photoreactor was kept at a distance of $\sim 40 \mathrm{~cm}$ from the light source. The incident light intensity $\left(10 \mathrm{~mW} / \mathrm{cm}^{2}\right)$ on the photoanode was measured with Lutron LX-101 Lux-meter. Under illumination without external bias, $0.01 \mathrm{ml}$ of hydrogen gas only evolved in $1 \mathrm{~h}$. Hence an external bias of $0.5 \mathrm{~V}$ was applied between the electrodes, so that the Fermi level is shifted and the electrons have the ability to reduce protons at the cathode.

\section{RESULTS AND DISCUSSION \\ 3.1 XRD analysis}

The XRD pattern of as-anodized and annealed titania nanotube is shown in fig. 1 . All the diffraction peaks present in fig. 1(a) corresponds to Ti substrate only and match with the hexagonal phase of pure $\alpha$-Ti (JCPDS card no. 89-5009). It is clearly seen that the as-anodized sample is amorphous in nature. On annealing crystalline anatase peaks of $\mathrm{TiO}_{2}$ are observed and shown in fig. 1(b-f). It clearly indicates that the annealing process induces the crystalline nature in titania nanotubes. In all the samples, major diffraction peaks corresponds to anatase while some traces of rutile phase are also observed. The peaks observed at $2 \theta=25.3^{\circ}, 37.8^{\circ}, 48.1^{\circ}, 53.8^{\circ}, 55.0^{\circ}$ corresponds to ( 10 1), ( ( $\left.\begin{array}{lll}0 & 0 & 4\end{array}\right),\left(\begin{array}{lll}1 & 1 & 2\end{array}\right),\left(\begin{array}{lll}1 & 0 & 5\end{array}\right),\left(\begin{array}{lll}2 & 1 & 1\end{array}\right)$ respectively and the values well coincide with the crystalline anatase (metastable) phase of $\mathrm{TiO}_{2}$ (JCPDS card no. 21-1272). The minor peaks presented at $2 \theta=27.4^{\circ}, 36.0^{\circ}, 54.0^{\circ}$ corresponds to (1 110$),\left(\begin{array}{lll}1 & 0 & 1\end{array}\right),\left(\begin{array}{lll}2 & 1 & 1\end{array}\right)$ respectively and match well with the high temperature stable phase of rutile (88-1175). The other peaks $\left(2 \theta=40.1^{\circ}, 53.0^{\circ}\right)$ corresponds to titanium substrate. By increasing the annealing time to 3 $\mathrm{h} \& 4 \mathrm{~h}$ the crystallinity increases substantially and the intensity of the (llll $\left.\begin{array}{lll}1 & 0 & 1\end{array}\right)$ anatase peak also gets increased greatly.

Table 1: XRD parameters for titania nanotubes of various annealing time

\begin{tabular}{|c|c|c|c|c|}
\hline \multirow{2}{*}{$\begin{array}{l}\text { Anneali } \\
\text { ng time } \\
\text { (h) }\end{array}$} & \multirow{2}{*}{$\begin{array}{l}\text { Integrated } \\
\text { Intensity of } \\
\text { (10 1) plane } \\
\text { (counts) }\end{array}$} & \multicolumn{2}{|c|}{ Lattice parameters $(\AA)$} & \multirow{2}{*}{$\begin{array}{c}\text { Cell } \\
\text { volume } \\
(\AA)^{3}\end{array}$} \\
\hline & & $a=b$ & c & \\
\hline 1 & 2897 & $3.7774(1)$ & $9.5208(7)$ & $135.89(1)$ \\
\hline 2 & 3256 & $3.7738(2)$ & $9.5163(6)$ & $135.23(1)$ \\
\hline 3 & 5398 & $3.7695(1)$ & $9.4769(6)$ & $134.68(1)$ \\
\hline 4 & 12527 & $3.7578(1)$ & $9.4621(7)$ & $133.43(1)$ \\
\hline 5 & 2784 & $3.7785(1)$ & $9.5193(7)$ & $135.92(1)$ \\
\hline
\end{tabular}

However the prolonged annealing $(5 \mathrm{~h})$ at $580{ }^{\circ} \mathrm{C}$ reduces the crystallinity of most photoactive anatase phase along with increasing rutile peak intensity. The average crystallite size of the anatase ( $\left(\begin{array}{lll}1 & 0 & 1\end{array}\right)$ peak is calculated using Scherrer's constant ${ }^{16}$ and it is found to be $\sim 41 \mathrm{~nm}$. The lattice parameters are calculated with the "UNIT CELL software" and given in Table 1 for comparison.

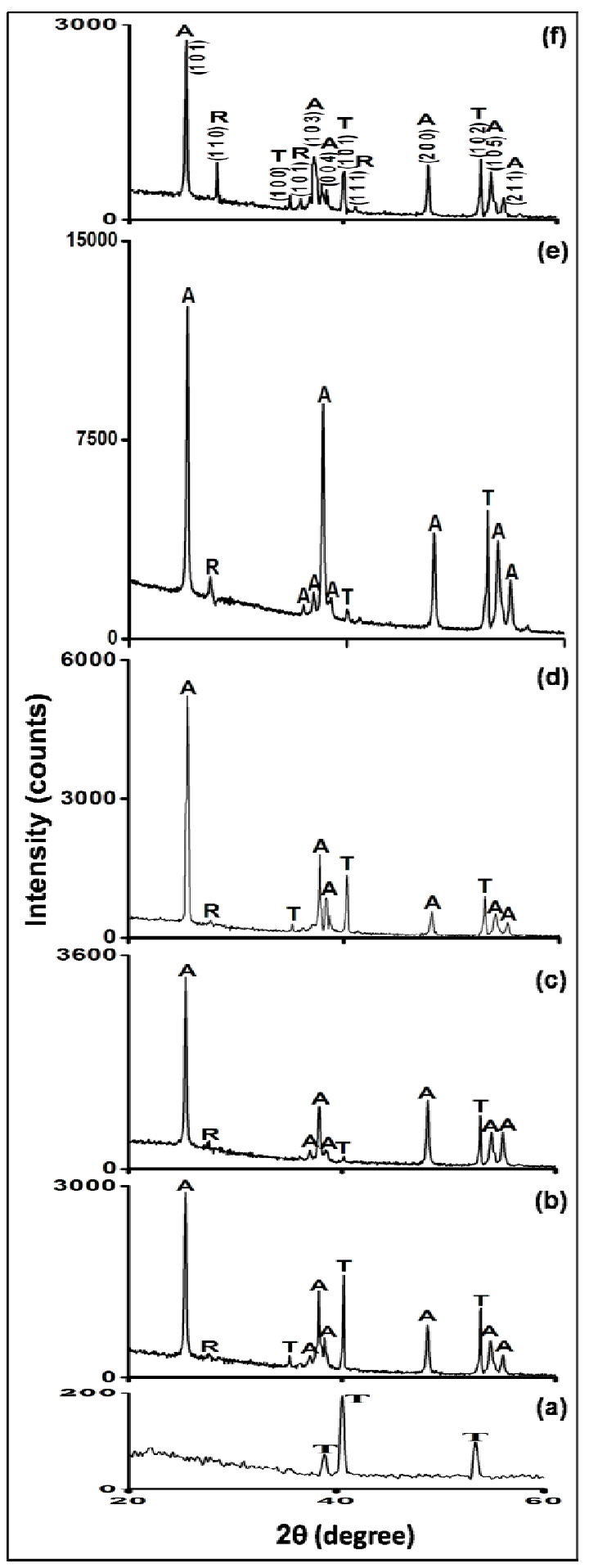

Fig. 1 XRD pattern of a) as-anodized and titania nanotube annealed at $580{ }^{\circ} \mathrm{C}$ for b) $1 \mathrm{~h}$, c) $2 \mathrm{~h}$, d) $3 \mathrm{~h}$, e) $4 \mathrm{~h}$ and f) $5 \mathrm{~h}$ (T-Titanium; A-Anatase; R-Rutile) 


\subsection{Morphological studies}

The surface morphology of the as-anodized and 3 $\mathrm{h}$ annealed samples are shown in fig. 2. The pores are not clearly seen in the as-anodized nanotubes and some tubes have broken like structure (fig. 2 (a)). The annealing process effectively changes the morphology of the titania nanotube arrays. Compared to as-anodized sample, uniform pores with cylindrical shape nanotubes are observed in the annealed sample (fig. 2(b)). The average diameter and length of the annealed nanotubes are $75 \mathrm{~nm}$ and $8.70 \mu \mathrm{m}$ respectively. The corresponding aspect ratio is 113 . The cross-sectional view of the annealed titania nanotube is shown in fig. 2(c), indicates that the tubes are grown vertically along the tube axis from the titanium substrate. The bottom view of the HR-SEM image shows that the nanotubes are highly ordered and densely arranged. The elemental composition of $\mathrm{TiO}_{2}$ is confirmed from EDS analysis and its spectrum is given in fig. 2(d). The observed Ti:O atomic ratio are nearly stoichiometric in the annealed sample and the results are well correlated with the earlier reported results. ${ }^{17,18}$

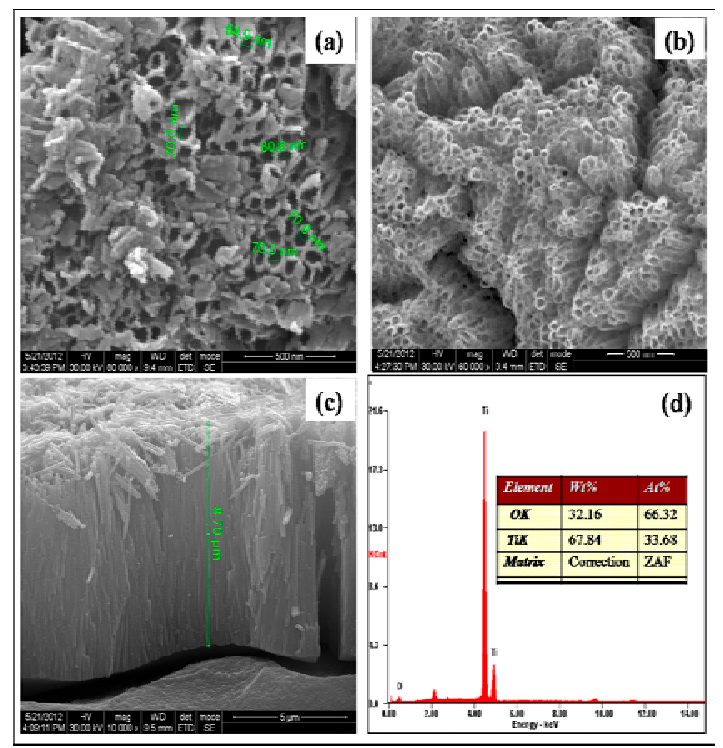

Fig. 2 HR-SEM images of a) as-anodized and $3 \mathrm{~h}$ annealed b) top view, c) cross-sectional view and d) EDS spectrum of titania nanotubes

\subsection{Optical Studies}

The effect of annealing time on band gap of titania nanotubes are analyzed using the reflectance spectra shown in fig. 3(a). The reflectance spectra were analyzed using Kubelka-Munk $(\mathrm{KM})$ relation ${ }^{19}, \mathrm{~F}\left(\mathrm{R}_{\infty}\right)=\left(1-\mathrm{R}_{\infty}\right)^{2} / 2$ $\mathrm{R}_{\infty}$, where $\mathrm{R}_{\infty}$ is the reflectance with respect to wavelength. The $\%$ of reflectance (fig. 3(a)) is found to decrease with annealing time depicting higher light absorption particularly in the visible region. Furthermore, the band edge shifts towards the higher wavelength, indicating the decrease of band gap. The optical band gaps are determined from KM graph (fig. 3(b)) by extrapolating the linear region of y-axis $\left(\mathrm{F}\left(\mathrm{R}_{\infty}\right) h v\right)^{1 / 2}$ to the $\mathrm{x}$-axis (hv) using least squares fitting analysis.

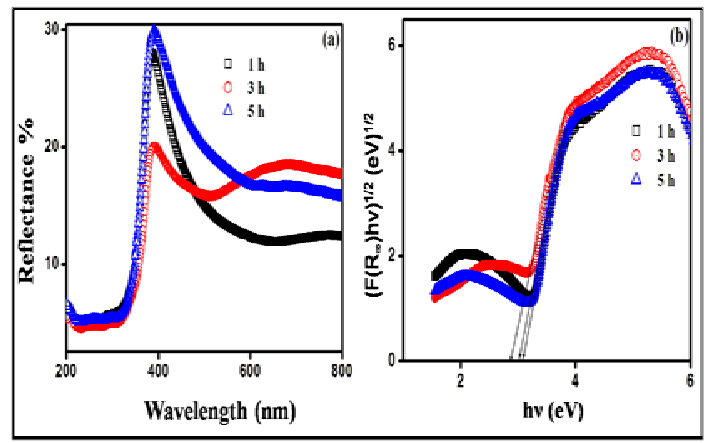

Fig. 3 a) Reflectance spectra and b) KM graph of titania nanotubes

The calculated band gap values for $1,3 \& 5 \mathrm{~h}$ annealed samples are 3.026 (3), 2.860 (1) and 3.084 (2) $\mathrm{eV}$ respectively. The reason for red and blue shift observed in $3 \& 5 \mathrm{~h}$ annealed sample is due to the creation of trapped energy levels in the forbidden gap.

\subsection{Photoelectrochemical studies}

In this experiment, the as-anodized and annealed titania nanotubes were used as photoanode and its photoelectrochemical parameters such as photocurrent density, photoconversion efficiency are studied. The asanodized amorphous titania nanotube shows a negliglible photoelectrochemical response and it is attributed to the poor crystallinity. Next the water splitting experiments were carried out for $1 \mathrm{~h}$ under constant external bias of 0.5 $\mathrm{V}$ under light irradiation without and with EG. The water splitting reaction was confirmed by the observation of $2: 1$ ratio of evolved hydrogen to oxygen and is given in Table 2 . The yield increases with increase in annealing time and also in the presence of organic additive EG. EG acts as a hole scavenger, prevents charge carrier recombination in titania nanotubes and thereby increase the yield of hydrogen generation. Moreover the improvement in crystallinity on annealing decreases the charge carrier recombination centers, which also aids water splitting. The maximum amount of hydrogen generation observed in $4 \mathrm{~h}$ annealed titania nanotube is attributed to the decrease in band gap value and improved crystallinity.

The photoconversion efficiency for the twoelectrode system is calculated using the relation, $\eta \%=j_{p}$ $\left(E_{0}-V_{\text {bias }}\right) / I_{0}$ where $j_{\mathrm{p}}$ is the photocurrent density, $E_{0}=1.23$ is the standard reversible potential for water splitting and $\mathrm{V}_{\text {bias }}$ is the applied bias between two electrodes respectively. ${ }^{20,21}$ The measured values are given in Table 2 for comparison. The photocurrent density and photoconversion efficiency increases with increase in annealing time and also the presence of organic additive EG. And also the experiments were done under dark condition. The measured dark photocurrent density for all the samples is about $0.001 \mathrm{~mA} / \mathrm{cm}^{2}$ and no water splitting. 
The maximum efficiency is observed in $4 \mathrm{~h}$ annealed samples and it clearly shows that crystallinity and in particular anatase phase plays an important role. The higher crystallinity and anatase phase with vertically oriented one dimensional nanotube provides larger surface area and faster electron transport pathways which results in increasing photoconversion efficiency. In $5 \mathrm{~h}$ annealed titania crystallinity is reduced drastically and also rutile phase emerges. The band gap energy is also greater than 4 $\mathrm{h}$ annealed one. All these features leads to the decrease in PEC performance in $5 \mathrm{~h}$ annealed titania.

Table 2: Photoelectrochemical performance of titania nanotubes annealed for different timings

\begin{tabular}{|c|c|c|c|c|c|c|}
\hline \multirow{2}{*}{$\begin{array}{c}\text { Annea } \\
\text { ling } \\
\text { time } \\
\text { (h) }\end{array}$} & \multicolumn{2}{|c|}{$\begin{array}{c}\mathrm{H}_{2} \text { evolved } \\
(\mathrm{ml} / \mathrm{h})\end{array}$} & \multicolumn{2}{|c|}{$\mathrm{j}_{\mathrm{p}}\left(\mathrm{mA} / \mathrm{cm}^{2}\right)$} & \multicolumn{2}{|c|}{$\eta \%$} \\
\hline & $\begin{array}{l}\text { WO } \\
\text { EG }\end{array}$ & $\begin{array}{l}\text { WE } \\
G\end{array}$ & $\begin{array}{l}\text { WO } \\
\text { EG }\end{array}$ & $\begin{array}{c}\text { WE } \\
\text { G }\end{array}$ & $\begin{array}{c}\text { WOE } \\
\text { G }\end{array}$ & WEG \\
\hline $1 \mathrm{~h}$ & 0.12 & 0.15 & 1.5 & 2.0 & $\begin{array}{l}10.9 \\
\end{array}$ & 14.6 \\
\hline $2 \mathrm{~h}$ & 0.13 & 0.16 & 1.6 & 2.2 & 11.68 & 16.06 \\
\hline $3 \mathrm{~h}$ & 0.14 & 0.18 & 1.8 & 2.4 & 13.14 & 17.52 \\
\hline $4 \mathrm{~h}$ & 0.21 & 0.24 & 2.1 & 2.6 & 15.33 & 18.98 \\
\hline $5 \mathrm{~h}$ & 0.13 & 0.16 & 1.6 & 2.1 & 11.68 & 15.33 \\
\hline
\end{tabular}

In XRD, $4 \mathrm{~h}$ annealed sample is more crystalline with anatase phase compared to others. This enhancement is not only due to increase in annealing time, but also to the higher content of anatase phase with lower band gap energy.

\section{REFERENCES}

[1] S. Ahuja and T.R.N. Kutty, J. Photochem. Photobiol. A., 97, 99-107 (1996).

[2] K.T. Ranjit, I. Willner, S.H. Bossmann and A.M.Braun, Environ. Sci. Technol., 35, 1544-1549 (2001).

[3] D.L. Liao and B.O. Liao, J Photochem Photobiol A 187, 363-369 (2007).

[4] A. Fujishima and K. Honda, Nature, 238, 37-38 (1972).

[5] K. Shankar, G.K. Mor, H.E. Prakasam, S. Yoriya, M. Paulose, O.K. Varghese and C.A. Grimes, Nanotechnology, 18, 065707-065718 (2007).

[6] G.K. Mor, K. Shankar, M. Paulose, O.K. Varghese and C.A. Grimes, Nano Lett., 6, 215-218 (2005).

[7] S. Yoriya, H.E. Prakasam, O.K. Varghese, K. Shankar, M. Paulose, G.K. Mor, T.J. Latempa and C.A. Grimes, Sens. Lett., 4, 334-339 (2006).

[8] V.K. Mahajan, S.K. Mohapatra and M. Misra, Int, J, Hydrogen Energy, 33, 5369-5374 (2008).

[9] K. Dai, T. Peng, D. Ke and B. Wei, Nanotechnology, 20, 125603-125609 (2009).

[10] A.L. Linsebigler, G. Liu and J.T. Yates, Chem. Rev., 95, 735-758 (1995).
The lower band gap energy leads to the absorption of visible region and thereby increase the higher photoconversion efficiency in titania nanotubes. Further increasing the annealing time to $5 \mathrm{~h}$, the photoelectrochemical response gets decreased, which is attributed to the decrease in anatase phase with increase in rutile peaks generation and also the blue shift observed in DRS studies. XRD result is well consistent with other results and also follows the same trend. It can be concluded that the higher crystallinity of anatase phase, annealing time, morphology, and lower band gap are the important factors to improve the photoelectrochemical response of titania nanotubes.

\section{CONCLUSIONS}

Annealing promotes the crystalline nature of titania nanotubes fabricated by two-step electrochemical anodization. The mixed phases of anatase and rutile of $\mathrm{TiO}_{2}$ are confirmed from XRD studies and $4 \mathrm{~h}$ annealed sample is more crystalline and anatase. The variation in the optical band gap with respect to annealing time is in agreement with the crystallinity observed from XRD analysis. The titania nanotubes with higher crystalline phase and lesser band gap energy exhibit the higher photoelectrochemical activity.

\section{ACKNOWLEDGEMENT}

The authors gratefully acknowledge Department of Science and Technology, Government of India (DST, Project No. SR/NM/NS-114/2010(G)) for their financial support in performing the present research work.

[11] S.G. Yang, Y.Z. Liu and C. Sun, Appl. Catal. A,, 301, 284-291 (2006).

[12] H.H. Ou and S.L. Lo, Sep. Purif. Technol., 58, 179191 (2007).

[13] G.K. Mor, O.K. Varghese, M. Paulose and C.A. Grimes, Adv. Funct. Mater., 15, 1291-1296 (2005).

[14] S.Q. Li, G.M. Zhang, D.Z. Guo, L.G. Yu and W.J. Zhang, J. Phys. Chem. C, 113, 12759-12765 (2009).

[15] N.K. Allam and C.A. Grimes, J. Phys. Chem. C, 113, 7996-7999 (2009).

[16] H.P. Klug and L.E. Alexander, X-ray Diffraction Procedures, John Wiley \& Sons, New York, 1959.

[17] X. Fan, Y. Zhang, P. Xiao, F. Hu and H. Zhang, Chin. J. Chem. Phys., 20, 753-758 (2007).

[18] Y. Xie, L. Zhou and H. Huang, Appl. Catal. B: Environ., 76, 15-23 (2007).

[19] I. Yang and B. Kruse, J. Opt. Sci. Am. A, 21, 19331941 (2004).

[20] O.J. Murphy and J.O.M. Bockris, Int. J. Hydrogen Energy, 9, 557-561 (1984).

[21] O.K. Varghese and C.A. Grimes, Sol. Energy Mater. Sol. Cells, 92, 374-384 (2008). 